\title{
The Need to Incorporate Autonomic Arousal in Developmental and Life-Course Research and Theories
}

\author{
Olivia Choy $^{1}$ - David P. Farrington ${ }^{2}$ - Adrian Raine ${ }^{3}$
}

Received: 27 November 2014 / Revised: 23 April 2015 / Accepted: 27 April 2015 /

Published online: 9 May 2015

(C) Springer International Publishing AG 2015

\begin{abstract}
Purpose Although there is an extensive body of research on the relationship between autonomic measures of physiological arousal and crime and delinquency, little effort has been made to incorporate autonomic arousal into criminological theories. This article examines the empirical literature on the associations between autonomic arousal and key constructs that are included in developmental and life-course theories, including temperament, cognition, life events, and family factors.

Method For an illustrative approach, this article specifically focuses on two measures of physiological arousal, heart rate and skin conductance.

Results Salient features of the literature include empirical findings that suggest that social factors can affect autonomic functioning and that autonomic arousal levels can contribute to individual differences in psychological risk factors for offending.

Conclusions A biopsychosocial model is proposed to show how autonomic arousal can be incorporated into extant criminological theories. If autonomic measures of arousal are included in future developmental and life-course research, the explanation and prediction of offending will be increased.
\end{abstract}

Keywords Autonomic arousal - Heart rate - Skin conductance - Developmental . Life course

Olivia Choy

ochoy@sas.upenn.edu

1 Department of Criminology, Jerry Lee Center of Criminology, University of Pennsylvania, 3809 Walnut St., Philadelphia, PA 19104, USA

2 Institute of Criminology, University of Cambridge, Sidgwick Avenue, Cambridge CB3 9DA, UK

3 Departments of Criminology, Psychiatry, and Psychology, Jerry Lee Center of Criminology, University of Pennsylvania, 3809 Walnut St., Philadelphia, PA 19104, USA 
Since the revival of biological explanations in criminology in the late twentieth century, criminology has developed from a social science-focused discipline to one that is increasingly aware of the contributions of biological sciences. For example, a substantial body of empirical research exists documenting biological factors as risk and protective factors for crime and delinquency [19, 63, 71, 98, 108, 140, 156]. In light of the relationship between biology and crime, some researchers have also begun to consider how biological factors might be incorporated in criminological theories such as Agnew's general strain theory [145], rational choice theory [1], Moffitt's developmental taxonomy [5, 6, 17, 18, 102], and Lahey and Waldman's [84] developmental model of the propensity to offend in children and adolescents.

Despite evidence that criminology is becoming more biologically informed, the extent to which biological variables are included differs across research and theories [155]. Biological studies tend to be viewed as having empirical merit in documenting a putative risk factor for antisocial behavior, but many theories still fail to incorporate biological influences or explain how such factors relate to antisocial behavior [1, 145, 151]. This failure to place biological factors in a theoretical context can limit the explanatory power of current criminological theories.

This article aims to address the conceptual gap between biology and criminology by examining the relationship between autonomic arousal and four social and psychological constructs that underlie developmental and life-course (DLC) theories. As DLC theories have been claimed to be more wide-ranging and encompassing than classic criminological theories, the usefulness of autonomic factors to DLC theories is the focus of this review [55].

First, we describe the role of autonomic measures of physiological arousal as possible causes of delinquent and criminal behavior, including a broad description of heart rate and skin conductance responses. The second section introduces a model through which autonomic arousal can be incorporated into DLC theories. Third, the empirical literature on the relationships between autonomic arousal and psychological and social constructs underlying DLC theories is reviewed and examples of how autonomic arousal can be incorporated into DLC theories are given. Fourth and last, we address future directions and challenges for the inclusion of autonomic measures in criminology.

\section{Autonomic Arousal}

The concept of an optimal level of arousal has contributed significantly to the contemporary understanding of biology in criminology $[49,74,115,160]$. Eysenck's arousalbased personality theory and Trasler's learning theory proposed that arousal rates are related to crime because conscience consists of a set of classically conditioned emotional responses to adverse environments [50, 139]. Lower levels of arousal cause poorer conditioning to environmental stimuli. It is assumed that the strength of the conscience depends on passive avoidance conditioning by parents. Impaired conditioning may result in the absence of or decrease in anticipatory anxiety regarding the consequences of a criminal or antisocial act, which causes a weak conscience. This in turn makes individuals less restrained and predisposes them to crime and antisocial behavior. Individuals with lower levels of arousal may engage in crime to raise their 
arousal to an optimal level. Aspects of Eysenck's theory have influenced research on biological factors in offending. Empirical studies have documented that autonomic underarousal is associated with crime and delinquency [40, 54, 77, 89, 107].

One index of arousal is autonomic nervous system activity. The autonomic nervous system is a subdivision of the peripheral nervous system that regulates involuntary functions [25]. It comprises of the sympathetic nervous system that is associated with the "fight or flight" response and the parasympathetic nervous system, which is associated with regulatory activity $[8,66]$. Specifically, psychophysiological measures are emphasized in this review. They constitute a valid method to determine arousal as physiological responses are universal, sensitive, and objective [89]. They have been used in prospective studies on criminal and antisocial outcomes $[3,63,77,90,116$, 151]. Psychophysiology is particularly useful in studying biological influences as specific measures have been identified. In contrast, in disciplines such as behavioral genetics, with the exception of the monoamine oxidase A (MAOA) gene, no single gene has been robustly identified as associated with crime and delinquency $[9,10,26,33,58,68,136]$. As cardiovascular functioning and electrodermal activity serve as the most popular measures of physiological response, this review is limited to these factors.

\section{Heart Rate}

Heart rate is influenced by the sympathetic and parasympathetic branches of the autonomic nervous system [16]. It is a particularly apt biological variable to assess in relation to crime, as low heart rate is a robust, well-replicated correlate of constructs relevant to criminal behavior $[48,130]$. Studies have revealed significant associations between low resting heart rate and other undesirable outcomes related to crime and delinquency such as antisocial behavior in children and adolescents and conduct problems (e.g., [89, 107, 109, 110]). A meta-analysis has also documented resting heart rate to be associated with both reactive and proactive aggression [109], although a recent study found that the association between resting heart rate and aggression was specific to proactive aggression after controlling for reactive aggression [117]. Moreover, there is some evidence that low heart rate may be associated particularly with non-psychopathic forms of antisocial behavior (e.g., $[3,110,117])$.

Similar relationships were observed when heart rate was assessed during a stressor [107]. The association between low heart rate and criminal and antisocial behavior has been found across different species of animals, cultures, and genders [37, 46, 89, 103 , 107, 116] and independently of potential confounds such as height, weight, smoking, and physical exercise $[2,35,77]$. Furthermore, heart rate is diagnostically specific, as low resting heart rate is associated with conduct disorder, but not with other psychiatric conditions [116].

There are two major theoretical interpretations of underarousal in delinquent and criminal individuals. The stimulation-seeking theory posits that underarousal prompts individuals to commit more antisocial acts as they seek stimulation to raise their arousal levels to an optimal level, while the fearlessness theory proposes that low levels of arousal indexes a low level of fear in individuals who may then be more likely to engage in antisocial behaviors that require a degree of fearlessness to execute $[2,114$, 
116, 142]. In an empirical study, Armstrong and Boutwell [1] concluded that fearlessness, measured by how individuals perceive the costs and benefits of offending, is a mechanism linking low heart rate to antisocial behavior. However, studies by Sijtsema et al. [134] and Portnoy et al. [110] found that impulsive sensation-seeking, rather than fearlessness, partially mediates the heart rate-antisocial behavior association. Thus, the underlying mechanism is unclear.

\section{Skin Conductance}

Unlike heart rate, electrodermal activity is regulated exclusively by the sympathetic nervous system [16]. The skin conductance level and number of nonspecific skin conductance responses measure electrical conductivity at the surface of the skin [59, 81]. Empirical studies have documented a negative relationship between skin conductance and criminal behavior and delinquency [48, 64, 82, 119]. A similar pattern of results has been observed for other types of antisocial behavior. Low resting electrodermal activity is associated with higher levels of adult psychopathy and aggressive behavior in children, specifically reactive aggression, while lower skin conductance measured during a task is associated with increased conduct problems and psychopathy in adolescents and adults $[89,112,131]$.

\section{Integrating Measures of Autonomic Arousal into DLC Theories}

\section{Biopsychosocial Model of Crime and Delinquency}

A biopsychosocial mediation model is proposed to conceptualize how biological characteristics fit into theories of delinquent and criminal behavior (Fig. 1). Variations of this mediation model have been suggested by other researchers. For example, the social neurocriminology perspective proposes that the social environment influences biological functions, in part, to predispose to antisocial and criminal behavior [38]. In another model, van Goozen et al. [140] proposed that family

$\underline{\text { Social Factors }} \quad \underline{\text { Biology }} \quad \underline{\text { Psychological }}$ $\underline{\text { Risk Factors }}$

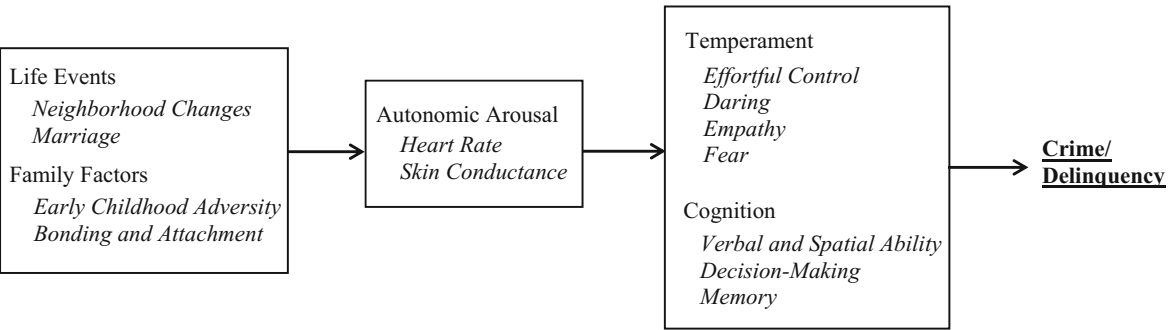

Fig. 1 The proposed biopsychosocial model. This model shows the pathways through which social factors (life events and family factors) lead to changes in biological functioning (autonomic arousal, measured by heart rate and skin conductance), which is in turn associated with psychological risk factors (temperament and cognition) that predispose to crime and delinquency. Subdimensions of each construct are listed in italics. Bold paths represent empirically informed pathways based on reviews of the literature 
factors influence antisocial behavior through biological, cognitive, and emotional mechanisms, while DeLisi and Vaughn [44] presented a model in which genotypes and neural substrates influence temperament to lead to problem behavior outcomes, all of which can be affected by contextual factors. This article builds on prior literature by (a) presenting a more encompassing framework for crime and delinquency that includes social environmental, biological, and psychological variables; (b) applying a biopsychosocial model to DLC research and theories; and (c) examining the biological factor of autonomic arousal.

In this model, social factors are hypothesized to lead to changes in biological functioning to some extent. Biological factors in turn lead to psychological risk factors that influence criminal and delinquent behavior. Such an approach is consistent with the notion that social causes of crime must act through psychological pathways [51], that psychological processes originate from physiological ones [81], and that models of criminal behavior should involve the integration of biological, psychological, and environmental characteristics [1, 43, 133, 140].

\section{Psychological Risk Factors}

\section{Temperament}

Temperament is the stable tendency by which an individual experiences and emotionally responds to the environment [44, 145]. While many categories of temperament exist [146], four dimensions of temperament are highlighted in the criminological literature, namely effortful control, daring, empathy, and fear.

Effortful Control Effortful control is a key feature of self-regulation. It is closely related to impulsivity and is often referred to as inhibitory control or self-control in developmental contexts $[44,59]$. It is the ability to suppress a dominant response in order to perform a subdominant one, as well as to modulate and maintain emotions, behaviors, and physiological reactions to achieve a goal $[39,125,126,149,154]$.

Studies have shown that lower arousal is associated with lower levels of effortful control. Lower resting heart rates were associated with faster responses in a risk game, indicating that autonomic underarousal is linked to impulsivity [132]. Similarly, Mathias and Stanford [95] found that underarousal was associated with individuals' ratings of impulsivity. Highly impulsive adults exhibited lower resting heart rates compared to those with normal scores on the impulsivity scale. This is further supported by a recent finding that low resting heart rate was significantly associated with higher impulsivity scores in children, controlling for age, sex, and other traits associated with child psychopathy [117].

Similarly, arousal during task periods has been assessed in relation to effortful control. Higher skin conductance levels measured during tasks were associated with higher effortful control ratings in children at age 4 years [59]. In a study involving an arousal challenge of different levels of intensity, more impulsive individuals had significantly lower heart rates than those with a normal range of impulsivity scores during the most challenging three of the four arousal tasks [95]. In addition, research on 
psychopathy, of which impulsivity is a component, has documented that psychopaths show lower electrodermal activity in the face of a stimulus [92, 157], providing support for the positive relationship between autonomic arousal and effortful control.

Daring The daring dimension of temperament refers to a style of reacting in the face of novel events $[61,124]$. It is characterized by a tendency towards sensation-seeking and novelty-seeking and has been regarded as the inverse of behavioral inhibition $[80,83,84]$.

Low resting heart rate has been linked to lower inhibition or high risk-taking behavior in children and adolescents $[110,123,134]$ as well as adults [45, 96, 132], even after controlling for a number of variables. A similar pattern of results has been found for arousal measured during a task. Greater heart rate levels were observed in inhibited compared to uninhibited children during a cognitive task [123]. In another study, participants' behaviors were analyzed during a control condition and after experiencing an arousal condition comprising of acute physical exercise that elevated their heart rate levels [132]. Participants were more likely to choose the safer option in a gambling task in the arousal condition compared to the control condition. The positive association between heart rate and behavioral inhibition has also been observed longitudinally [79]. Although evidence of a low arousal-high sensation seeking relationship is less consistent in females $[152,153]$ and for the measure of skin conductance [45], empirical studies have found substantial support for the relationship between low autonomic arousal and a more daring temperament.

Empathy A third dimension of temperament, empathy, refers to concern for the feelings of others [84]. Zahn-Waxler, Cole, Welsh, and Fox [158] found that higher heart rates, measured both during a sadness mood induction period and a non-mood induction period, were associated with greater empathic concern, emotional arousal, and prosocial behavior. On the other hand, lower heart rates were consistently associated with avoidance and joy during another's distress. Findings from more recent studies support these conclusions, as lower heart rate was strongly and consistently associated with active disregard reflected by negative and aggressive responses to others' distress [141] and higher heart rate was associated with greater empathy and likelihood of intervening to help [4, 87]. These results are consistent with the notion that individuals who are highly aroused are more likely to be disregulated and distressed when confronted with another's distress, motivating them to be prosocial in order to alleviate their own distress [52].

Fear Within the limited research on the association between autonomic arousal and fear, evidence has been found for an association between a higher resting heart rate and more fear in children [31, 80], as well as distress responses [52, 60, 149].

\section{Integration of Autonomic Arousal into DLC Theories involving Temperament}

Taken together, the results from various studies on temperament provide some evidence that individual differences in autonomic arousal can affect temperament in child and adult populations. It may be beneficial then, to incorporate arousal into temperamentbased theories. For example, DeLisi and Vaughn's [44] temperament-based theory 
suggests that reduced effortful control and negative emotionality produces antisocial conduct throughout life and explains people's failure to interact with criminal justice practitioners and complete correctional sentences. Individuals with such temperament may have lower social competence, low levels of self-constraint, and difficulty disengaging with negative or threatening stimuli, resulting in blaming others, becoming easily annoyed, and frequently losing their temper. Effortful control also predicts outcomes such as greater depression and higher likelihood of drug dependence, which are associated with criminal behavior [101]. Based on the empirical findings, higher autonomic arousal may lead to better effortful control, which results in better ability to regulate attention, emotion, and behavior to function according to societal rules. In a similar way, autonomic measures can be incorporated into Lahey and Waldman's [84] DLC theory of the propensity to offend during childhood and adolescence, which proposes that the daring, prosociality, and negative emotionality dimensions contribute to the antisocial propensity of individuals. Thus, low levels of autonomic arousal can help to explain differences in temperament that have been shown to predict later offending.

\section{Cognition}

Cognitive functioning, in terms of verbal and spatial ability, decision-making, and memory processes, is influenced by states of physiological arousal. Although it has been suggested that among males, change in noncognitive skills has a larger effect on criminal behavior, measured by probability of incarceration, compared to a corresponding change in cognitive skills [75], cognition has been shown to be linked to delinquency later in life and in persistently antisocial individuals [104, 122]. It is a construct that is central to a number of DLC theories.

Verbal and Spatial Ability Greater autonomic activity is positively associated with verbal ability, measured by memory for words [27]. Through three verbal memory tasks, differences in skin conductance responding to arousing word groups, namely taboo and unpleasant words, predicted subsequent recall. Words that elicited greater skin conductance responses were better remembered, suggesting that greater autonomic responses to individual words influence better subsequent memory. Additionally, studies have found that higher blood pressure, which is positively correlated with heart rate [105, 159], is linked to better visuospatial performance [94, 147].

Decision-Making Physiological factors are also associated with decision-making [11]. In a study by Armstrong and Boutwell [1], individuals with a low resting heart rate perceived a lower likelihood of arrest for theft and drunk driving and were less likely to anticipate a sense of guilt or shame if they committed an assault during a confrontation. In this way, low resting heart rate was associated with consideration of the costs and benefits of offending. This is consistent with a prior study documenting that higher arousal, measured by heart rate during a complex mental activity, was associated with better performance in solving complex logical problems [15]. The relationship between arousal and decision-making, however, is more consistently observed among males [14]. 
Memory Processes Autonomic measures of arousal at baseline and during recall and recognition tasks are also related to memory processes, with greater autonomic activity associated with better memory. Individuals with higher heart rates at baseline and during cognitive tasks, such as Digit Symbol and Symbology tasks, performed better than those with lower heart rates [29, 32]. This finding is replicated with electrodermal activity. Higher skin conductance responses were linked to improved memory [21]. However, there is evidence to suggest that the arousal-memory relationship depends on the level of cognitive demand of the task. High levels of arousal have been associated with better performance on more cognitively demanding tasks such as long-term memory tests compared to immediate tests $[28,41]$ and in a more rigorous $n$-back working memory task compared to an easier letter memory task [36].

\section{Integration of Autonomic Arousal into DLC Theories Involving Cognition}

In DLC theories, it can be proposed that autonomic arousal causes individual differences in cognitive abilities. In this way, incorporating autonomic arousal can help to better explain extant DLC theories. For example, lower resting heart rates predicted life-course persistent offenders, but not adolescence-limited offenders in Moffitt's [100] developmental taxonomy [102]. As cognitive deficits are linked to life-course persistent, but not adolescence-limited offenders, autonomic arousal may account for the neuropsychological variation that increases risk for life-course persistent offending [100]. In addition, autonomic arousal can influence verbal ability, which constitutes one of the most important factors contributing to antisocial propensity in Lahey and Waldman's [84] model. It can also influence cognitive processes such as thinking and decision-making that contribute to whether antisocial potential translates into crime and antisocial behavior as in Farrington's [56] integrated cognitive antisocial potential (ICAP) theory. It has been proposed that autonomic arousal facilitates learning through its effect on the brain, by establishing a level of cortical excitation without which learning cannot occur [74]. Thus, low levels of autonomic arousal may result in poorer cognitive abilities that affect individuals later in life such as in the form of fewer options to pursue legitimate employment [100] and poor decision-making when weighing the perceived costs and benefits of offending [1], that then lead to crime and delinquency.

\section{Social Risk Factors}

\section{Life Events}

An increasing body of research shows that social variables can influence autonomic system functioning $[47,72,91,143]$. More specifically, social factors in the form of life events such as neighborhood changes and marriage have been studied in relation to autonomic measures. For example, there is evidence of an effect of migration on higher blood pressure, which is positively correlated with heart rate [105, 159], that is significant even controlling for factors such as weight change and selective migration, particularly among men. These findings are consistent across different countries including New Zealand [7, 128], Italy [99], Africa [113], and China [73]. In addition, 
marital status is associated with cardiovascular functioning, as married individuals had higher ambulatory blood pressures than single individuals [76].

Integration of Autonomic Arousal Into DLC Theories involving Life Events DLC theories such as Sampson and Laub's [129] age-graded theory notes that life events in adulthood inhibit offending and foster desistance from crime, while the ICAP theory suggests that life events affect individuals' long-term antisocial potential, which in turn affects criminal behavior [56]. Although research on the relationship between life events and autonomic arousal is limited and the mechanisms underlying the association are unclear, the findings suggest that the understanding of desistance in DLC theories can be improved by noting that life events can affect criminal behavior, in part, through their effects on autonomic functioning.

\section{Family Factors}

Family factors are included in most DLC theories, and variables such as bad parenting have long been acknowledged as causes of crime and delinquency. Findings have supported a negative relationship between family factors and autonomic arousal as children who had experienced separation from the home before age 4 years had lower pulse rates at age 11 compared to children from intact homes [143]. The association between poor social bonds and low arousal is supported by the finding that low arousal is associated with low empathy [89, 141, 158], which is required for bonding and attachment [20, 24, 78, 85]. However, the relationship between family factors and autonomic arousal is not clear cut as some conflicting results have been documented. One study noted no significant difference in resting heart rate and skin conductance levels between abused children and matched controls [34], while others have found that poor quality of caretaking is associated with higher heart rates in offspring [12, 91, 137]. These inconsistencies may be attributable to family context and future research should recognize family context as a critical factor to consider in assessing the longterm physiological impact of family factors [127].

\section{Integration of Autonomic Arousal Into DLC Theories Involving Family} Factors The association between family factors and autonomic measures of physiological arousal suggests that autonomic arousal can be incorporated into DLC theories in which family factors play a role, such as Sampson and Laub's [129] general agegraded theory and Thornberry and Krohn's [138] interactional theory. Sampson and Laub [129] propose that family factors such as parental discipline and supervision contribute to the strength of bonding between individuals and parents, which in turn tends to inhibit offending. Thornberry and Krohn [138] propose that parenting deficits, characterized by poor monitoring, low affective ties, and physical punishment contributes to the early manifestation of antisocial behavior in children from birth to 6 years of age, compared to late starters who begin to engage in antisocial behavior from ages 18 to 25 years. The explanations of offending in these theories can be improved by considering that family factors may lead to crime and delinquency partly through their influence on individuals' levels of autonomic arousal. For example, negative parenting experiences early in a child's life can result in long-term chronic exposure to stress 
which imposes a biological burden on individuals' physiological systems [97]. This can lead to downregulation of physiological responses, which may help to explain in part how family factors are associated with offending throughout the life course.

\section{Addressing Key DLC Issues Using Autonomic Arousal}

Autonomic measures of physiological arousal can also contribute to DLC theories by shedding light on key empirical and theoretical issues, such as desistance, the explanation of within-individual differences in offending, the contribution of learning and decision-making processes in offending, and findings that may challenge DLC theory.

\section{Protective Factors}

One important issue that can be addressed with the incorporation of autonomic arousal lies in the understanding of factors that inhibit offending and the explanation of factors influencing desistance [55]. Psychological and social factors such as attachment and socialization processes [56] and life events [148] have been proposed in DLC theories as variables that inhibit offending. However, such theories do not consider the role of biological factors as possible protective factors in the development of crime and delinquency. High autonomic functioning, measured by resting heart rate and skin conductance levels, has been documented to protect against criminal and antisocial behavior [22, 108, 120]. Similar results have been obtained for orienting and fear conditioning [120,121]. To address this issue, it would be desirable to incorporate autonomic measures of physiological arousal in DLC theories.

\section{Within-Individual Change}

Autonomic arousal in DLC research can also aid in explaining within-individual differences in offending. The heart rate-antisocial behavior relationship has been confirmed in both cross-sectional and prospective longitudinal research, suggesting that heart rate predicts offending in spite of change in age. However, studies have not examined whether change in an individual's heart rate and skin conductance level over time explains offending over time. Analyses of within-individual changes in autonomic arousal, psychological risk factors, and later offending can help to establish causal relations as such analyses allow for the controlling of possible between-group factors that can influence offending, as well as the determination of causal order $[53,106]$. Obtaining a more accurate picture of how changes in these constructs affect changes in behavior can enable us to gain a better understanding of the development and causes of offending.

\section{Learning and Decision-Making Processes}

Another key issue raised in relation to DLC theories is whether there is a learning or decision-making process for offending [55]. As Fig. 1 suggests that autonomic arousal 
influences these cognitive processes to lead to offending, autonomic arousal can play an important role in addressing this key theoretical issue.

\section{Challenges to the Theory}

It is also important to address what findings might challenge the theory shown in Fig. 1. Although some empirical support for the proposed model has been documented [38], one study found that the relationship between resting heart rate and antisocial behavior in children was almost entirely explained by genetic influences [3]. With the dearth of replicated studies, additional research on autonomic arousal can reveal whether findings that challenge the model exist and thus, shed light on this important issue raised in DLC criminology.

\section{Conclusion}

Research on autonomic measures of physiological arousal supports the incorporation of such constructs in DLC theories. While similar models to Fig. 1 have been suggested to explain antisocial behavior, by proposing an integrative biopsychosocial mediation framework that builds on existing models, this article demonstrates how biological measures such as autonomic arousal can complement and add coherence to existing DLC theories. The proposed model suggests a biological factor, autonomic arousal, as an explanatory construct that is missing in extant DLC theories. For example, as depicted in Fig. 1, autonomic arousal may serve as a mechanism linking social factors, such as life events and family factors that are described in Sampson and Laub's [129] theory, to crime and delinquency. Examining changes in autonomic arousal after experiencing turning points in life and including this missing construct in the theory can thus provide a more complete understanding of the processes leading to offending. This can result in the development of a more comprehensive theory regarding the etiology of criminal and delinquent behavior, adding coherence.

Although this review refers specifically to DLC theories, autonomic arousal can also be incorporated into classical criminological theories. For instance, autonomic arousal is associated with self-control [59, 132], which forms the foundation of Gottfredson and Hirschi's [69] general theory of crime. Additionally, autonomic arousal is associated with poor parenting, an underlying construct in differential association theory [135].

This review is limited to autonomic arousal. However, other biological constructs, including genetic factors, brain deficits, and hormones, can also be incorporated into DLC theories. For instance, brain functioning in the prefrontal executive attention system and parahippocampal gyri has been linked to temperamental and cognitive dimensions [23, 111, 144], while increased striatum volume is linked to reward-seeking in the form of anticipation of monetary awards, which is in turn associated with motives for committing crime [67]. As another example, life events such as marriage [70], involvement in a committed, romantic relationship [30], and fatherhood [65] are associated with lower levels of testosterone in males. Future research could involve using the biopsychosocial model as a conceptual framework to empirically test how social factors may influence biological factors and psychological variables to lead to 
crime and delinquency later in life. Including other biological factors and adverse social stimuli can result in the development of more complex models. Additionally, possible moderating effects can be taken into account. For example, social factors have been found to moderate the relationship between risky decision-making and antisocial behavior [62]. Thus, examining possible moderating effects on the proposed mediation model would be revealing. Relatedly, it would be valuable to expand on the model longitudinally to reflect additional relationships, such as the possible influence of offending on life events and family factors.

In incorporating autonomic measures of physiological arousal in DLC research and theories, there are some practical benefits and constraints to consider. One primary challenge lies in the need for expertise and experience in conducting psychophysiological tests. Other practical issues involve the need for equipment for data collection, the choice of task during the measurement of psychophysiological arousal as results may be influenced by speech or the level of cognitive demand of the task [150], the temperature of the environment, and the placement of electrodes to reduce motion artifacts. Despite the need for training in collecting psychophysiological data, psychophysiological measures are advantageous as they are easier to record and less invasive than many other biological measures. This is particularly true for heart rate. They do not require laboratory conditions and can be measured in community surveys. These features are especially beneficial for longitudinal studies that may take place in multiple environments. Autonomic measures can also be recorded continuously without severely limiting activity and movement, and several variables can be obtained at once. For example, besides resting heart rate or heart rate measured during a task, vagal tone and heart rate variability can be obtained from the data. These benefits render psychophysiological measures apt to include in DLC research.

Several major longitudinal studies in criminology have employed such autonomic measures. For example, cardiovascular functioning has been measured in the Cambridge Study in Delinquent Development [57], the Individual Development and Adaptation Research Program [13, 93], the Mater University Study of Pregnancy [86], and the Dunedin Multi-Disciplinary Health and Development Study [103], while the Mauritius Child Health Project [118] and the Pittsburgh Youth Study [88] have included measures of electrodermal activity in addition to heart rate. In light of the ease of measurement, autonomic measures of arousal should be included in future prospective longitudinal studies. Increasingly, researchers are acknowledging that criminological theories that do not include biological influences of criminal behavior might be limited in scope and incomplete in their potential for contribution [42, 151]. This article makes progress towards this goal by showing how autonomic arousal can be incorporated in DLC theories.

\section{References}

1. Armstrong, T. A., \& Boutwell, B. B. (2012). Low resting heart rate and rational choice: integrating biological correlates of crime into criminological theories. Journal of Criminal Justice, 40(1), 31-39.

2. Armstrong, T. A., Keller, S., Franklin, T. W., \& MacMillan, S. N. (2009). Low resting heart rate and antisocial behavior: a brief review of evidence and preliminary results from a new test. Criminal Justice and Behavior, 36(11), 1125-1140. 
3. Baker, L. A., Tuvblad, C., Reynolds, C., Zheng, M., Lozano, D. I., \& Raine, A. (2009). Resting heart rate and the development of antisocial behavior from age 9 to 14: genetic and environmental influences. Development and Psychopathology, 21(3), 939-960.

4. Barhight, L. R., Hubbard, J. A., \& Hyde, C. T. (2013). Children's physiological and emotional reactions to witnessing bullying predict bystander intervention. Child Development, 84(1), 375-390.

5. Barnes, J. C. (2013). Analyzing the origins of life-course-persistent offending: a consideration of environmental and genetic influences. Criminal Justice and Behavior, 40(5), 519-541.

6. Barnes, J. C., Beaver, K. M., \& Boutwell, B. B. (2011). Examining the genetic underpinnings to Moffitt's developmental taxonomy: a behavioral genetic analysis. Criminology, 49(4), 923-954.

7. Beaglehole, R., Eyles, E., \& Prior, I. (1979). Blood pressure and migration in children. International Journal of Epidemiology, 8(1), 5-10.

8. Beauchaine, T. (2001). Vagal tone, development, and Gray's motivational theory: toward an integrated model of autonomic nervous system functioning in psychopathology. Development and Psychopathology, 13(2), 183-214.

9. Beaver, K. M., DeLisi, M., Vaughn, M. G., \& Barnes, J. C. (2010). Monoamine oxidase a genotype is associated with gang membership and weapon use. Comprehensive Psychiatry, 51(2), 130-134.

10. Beaver, K. M., DeLisi, M., Vaughn, M. G., \& Wright, J. P. (2010). The intersection of genes and neuropsychological deficits in the prediction of adolescent delinquency and low self-control. International Journal of Offender Therapy and Comparative Criminology, 54(1), 22-42.

11. Bechara, A., \& Damasio, A. R. (2005). The somatic marker hypothesis: a neural theory of economic decision. Games and Economic Behavior, 52(2), 336-372.

12. Bell, B. G., \& Belsky, J. (2008). Parenting and children's cardiovascular functioning. Child: Care, Health and Development, 34(2), 194-203.

13. Bergman, L. R. (2000). Women's health, work, and education in a life-span perspective. Technical report 1: theoretical background and overview of the data collection (Report from the project Individual Development and Adaptation No. 70). Stockholm: Stockholm University, Department of Psychology.

14. Blascovich, J., Nash, R. F., \& Ginsburg, G. P. (1978). Heart rate and competitive decision making. Personality and Social Psychology Bulletin, 4(1), 115-118.

15. Blatt, S. J. (1961). Patterns of cardiac arousal during complex mental activity. Journal of Abnormal and Social Psychology, 63(2), 272-282.

16. Boucsein, W. (1992). Electrodermal activity. New York: Plenum Press.

17. Boutwell, B. B., Barnes, J. C., Deaton, R., \& Beaver, K. M. (2013). On the evolutionary origins of lifecourse persistent offending: a theoretical scaffold for Moffitt's developmental taxonomy. Journal of Theoretical Biology, 322, 72-80.

18. Boutwell, B. B., \& Beaver, K. M. (2008). A biosocial explanation of delinquency abstention. Criminal Behavior and Mental Health, 18(1), 59-74.

19. Boutwell, B. B., Menard, S., Barnes, J. C., Beaver, K. M., Armstrong, T. A., \& Boisvert, D. (2014). The role of gene-gene interaction in the prediction of criminal behavior. Comprehensive Psychiatry, 55(3), 483-488.

20. Bowlby, J. (1982). Attachment (2nd ed.). New York: Basic Books.

21. Bradley, M. M., Greenwald, M. K., Petry, M. C., \& Lang, P. J. (1992). Remembering pictures: pleasure and arousal in memory. Journal of Experimental Psychology. Learning, Memory, and Cognition, 18(2), 379-390.

22. Brennan, P. A., Raine, A., Schulsinger, F., Kirkegaard-Sorensen, L., Knop, J., Hutchings, B., Rosenberg, R., \& Mednick, S. A. (1997). Psychophysiological protective factors for male subjects at high risk for criminal behavior. American Journal of Psychiatry, 154(6), 853-855.

23. Brewer, J. B., Zhao, Z., Desmond, J. E., Glover, G. H., \& Gabrieli, J. D. (1998). Making memories: brain activity that predicts how well visual experience will be remembered. Science, 281(5380), 1185-1187.

24. Britton, P. C., \& Fuendeling, J. M. (2005). The relations among varieties of adult attachment and the components of empathy. Journal of Social Psychology, 145(5), 519-530.

25. Brodal, P. (2004). The central nervous system: structure and function. New York: Oxford University Press.

26. Brunner, H. G., Nelen, M., Breakefield, X. O., Ropers, H. H., \& Van Oost, B. A. (1993). Abnormal behavior associated with a point mutation in the structural gene for monoamine oxidase A. Science, 262(5133), 578-580.

27. Buchanan, T. W., Etzel, J. A., Adolphs, R., \& Tranel, D. (2006). The influence of autonomic arousal and semantic relatedness on memory for emotional words. International Journal of Psychophysiology, 61(1), 26-33. 
28. Burbridge, J. A., Larsen, R. J., \& Barch, D. M. (2005). Affective reactivity in language: the role of psychophysiological arousal. Emotion, 5(2), 145-153.

29. Burgess, M., \& Hokanson, J. E. (1964). Effects of increased heart rate on intellectual performance. Journal of Abnormal and Social Psychology, 68(1), 85-91.

30. Burnham, T. C., Chapman, J. F., Gray, P. B., McIntyre, M. H., Lipson, S. F., \& Ellison, P. T. (2003). Men in committed, romantic relationships have lower testosterone. Hormones and Behavior, 44(2), 119-122.

31. Calkins, S. D., Dedmon, S., Gill, K., Lomax, L., \& Johnson, L. (2002). Frustration in infancy: implications for emotion regulation, physiological processes, and temperament. Infancy, 3(2), 175-198.

32. Capuana, L. J., Dywan, J., Tays, W. J., \& Segalowitz, S. J. (2012). Cardiac workload and inhibitory control in younger and older adults. Biological Psychology, 90(1), 60-70.

33. Caspi, A., McClay, J., Moffitt, T. E., Mill, J., Martin, J., Craig, I. W., Taylor, A., \& Poulton, R. (2002). Role of genotype in the cycle of violence in maltreated children. Science, 297(5582), 851-854.

34. Carrey, N. J., Butter, H. J., Persinger, M. A., \& Bialik, R. J. (1995). Physiological and cognitive correlates of child abuse. Journal of the American Academy of Child \& Adolescent Psychiatry, 34(8), 1067-1075.

35. Cauffman, E., Steinberg, L., \& Piquero, A. R. (2005). Psychological, neuropsychological and physiological correlates in serious antisocial behaviors in adolescence: the role of self-control. Criminology, 43(1), 133-175.

36. Cellini, N., Zambotti, M., Covassin, N., Sarlo, M., \& Stegagno, L. (2014). Working memory impairment and cardiovascular hyperarousal in young primary insomniacs. Psychophysiology, 51(2), 206-214.

37. Cherkovich, G. M., \& Tatoyan, S. K. (1973). Heart rate (radiotelemetrical registration) in macaques and baboons according to dominant-submissive rank in a group. Folia Primatologica, 20(4), 265-273.

38. Choy, O., Raine, A., Portnoy, J., Rudo-Hutt, A., Gao, Y., \& Soyfer, L. (2015). The mediating role of heart rate on the social adversity-antisocial behavior relationship: a social neurocriminology perspective. Journal of Research in Crime and Delinquency, 52(3), 303-341.

39. Cole, P. M., Martin, S. E., \& Dennis, T. A. (2004). Emotion regulation as a scientific construct: methodological challenges and directions for child developmental research. Child Development, 75(2), 317-333.

40. Cornet, L. J. M., de Kogel, C. H., Nijman, H. L. I., Raine, A., \& van der Laan, P. H. (2013). Neurobiological factors as predictors of cognitive-behavioral therapy outcome in individuals with antisocial behavior: A review of the literature. International Journal of Offender Therapy and Comparative Criminology, 1-18.

41. Craik, F. I. M., \& Blankstein, K. R. (1975). Psychophysiology and human memory. In P. H. Venables \& M. J. Christie (Eds.), Research in psychophysiology. New York: Wiley.

42. DeLisi, M. (2012). Genetics: L'enfant terrible of criminology. Journal of Criminal Justice, 40(6), 515516.

43. DeLisi, M., Beaver, K. M., Wright, J. P., \& Vaughn, M. G. (2008). The etiology of criminal onset: the enduring salience of nature and nurture. Journal of Criminal Justice, 36(3), 217-223.

44. DeLisi, M., \& Vaughn, M. G. (2014). Foundation for a temperament-based theory of antisocial behavior and criminal justice system involvement. Journal of Criminal Justice, 42(1), 10-25.

45. De Pascalis, V., Valerio, E., Santoro, M., \& Cacace, I. (2007). Neuroticism-anxiety, impulsive-sensation seeking and autonomic responses to somatosensory stimuli. International Journal of Psychophysiology, 63(1), 16-24.

46. Eisermann, K. (1992). Long-term heart rate responses to social stress in wild European rabbits: predominant effect of rank position. Physiology \& Behavior, 52(1), 33-36.

47. Ellis, B. J., \& Boyce, W. T. (2008). Biological sensitivity to context. Current Directions in Psychological Science, 17(3), 183-187.

48. Ellis, L., Beaver, K., \& Wright, J. (2009). Handbook of crime correlates. Kidlington, Oxford: Academic.

49. Eysenck, H. J. (1967). The biological basis of personality. Springfield, IL: Charles C. Thomas Publisher Ltd.

50. Eysenck, H. J. (1977). Crime and personality (3rd ed.). London: Routledge \& Kegan Paul.

51. Eysenck, H. J. (1996). Personality and crime: where do we stand. Psychology Crime and Law, 2(3), 143152.

52. Fabes, R. A., Eisenberg, N., Karbon, M., Troyer, D., \& Switzer, G. (1994). The relations of children's emotion regulation to their vicarious emotional responses and comforting behaviors. Child Development, 65(6), 1678-1693.

53. Farrington, D. P. (1988). Studying changes within individuals: the causes of offending. In M. Rutter (Ed.), Studies of psychosocial risk: the power of longitudinal data (pp. 158-183). Cambridge, UK: Cambridge University Press. 
54. Farrington, D. P. (1997). The relationship between low resting heart rate and violence. In A. Raine, P. A. Brennan, D. P. Farrington, \& S. A. Mednick (Eds.), Biosocial bases of violence. New York: Plenum.

55. Farrington, D. P. (2005). Introduction to integrated developmental and life-course theories of offending. In D. P. Farrington (Ed.), Integrated developmental \& life-course theories of offending: advances in criminological theory (Vol. 14). New Brunswick, New Jersey: Transaction Publishers.

56. Farrington, D. P. (2005). The integrated cognitive antisocial potential (ICAP) theory. In D. P. Farrington (Ed.), Integrated developmental \& life-course theories of offending: advances in criminological theory (Vol. 14). New Brunswick, New Jersey: Transaction Publishers.

57. Farrington, D. P., Piquero, A. R., \& Jennings, W. G. (2013). Offending from childhood to late middle age: recent results from the Cambridge Study in Delinquent Development. New York: Springer.

58. Fergusson, D. M., Boden, J. M., Horwood, L. J., Miller, A. L., \& Kennedy, M. A. (2011). MAOA, abuse exposure and antisocial behaviour: 30-year longitudinal study. The British Journal of Psychiatry, 198(6), $457-463$.

59. Fowles, D. C., Kochanska, G., \& Murray, K. (2000). Electrodermal activity and temperament in preschool children. Psychophysiology, 37(6), 777-787.

60. Fox, N. A. (1989). Heart-rate variability and behavior reactivity: individual differences in autonomic patterning and their relation to infant and child temperament. In J. S. Reznick (Ed.), Perspectives on behavioral inhibition. Chicago: University of Chicago Press.

61. Fox, N. A., Henderson, H. A., Marshall, P. J., Nichols, K. E., \& Ghera, M. M. (2005). Behavioral inhibition: linking biology and behavior within a developmental framework. Annual Review of Psychology, 56, 235-262.

62. Gao, Y., Baker, L. A., Raine, A., Wu, H., \& Bezdjian, S. (2009). Brief report: interaction between social class and risky decision-making in children with psychopathic tendencies. Journal of Adolescence, 32(2), 409-414.

63. Gao, Y., Glenn, A. L., Peskin, M., Rudo-Hutt, A., Schug, R. A., Yang, Y., \& Raine, A. (2011). Neurocriminological approaches. In D. Gadd, S. Karstedt, \& S. Messner (Eds.), Sage handbook of criminological research methods. London: Sage.

64. Gatzke-Kopp, L. M., Raine, A., Loeber, R., Stouthamer-Loeber, M., \& Steinhauer, S. R. (2002). Serious delinquent behavior, sensation seeking, and electrodermal arousal. Journal of Abnormal Child Psychology, 30(5), 477-486.

65. Gettler, L. T., McDade, T. W., Feranil, A. B., \& Kuzawa, C. W. (2011). Longitudinal evidence that fatherhood decreases testosterone in human males. Proceedings of the National Academy of Sciences, 108(39), 16194-16199.

66. Gilissen, R., Koolstra, C. M., van Ijzendoorn, M. H., Bakermans-Kranenburg, M. J., \& van der Veer, R. (2007). Physiological reactions of preschoolers to fear-inducing film clips: effects of temperamental fearfulness and quality of the parent-child relationship. Developmental Psychobiology, 49(2), 187-195.

67. Glenn, A. L., Raine, A., Yaralian, P. S., \& Yang, Y. (2010). Increased volume of the striatum in psychopathic individuals. Biological Psychiatry, 67(1), 52-58.

68. Goldman, D., \& Ducci, F. (2007). The genetics of psychopathic disorders. In A. R. Felthous \& H. Sa (Eds.), International handbook on psychopathic disorders and the law: volume 1. West Sussex, England: John Wiley \& Sons Ltd.

69. Gottfredson, M. R., \& Hirschi, T. (1990). A general theory of crime. Stanford: Stanford University Press.

70. Gray, P. B., Kahlenberg, S. M., Barrett, E. S., Lipson, S. F., \& Ellison, P. T. (2002). Marriage and fatherhood are associated with lower testosterone in males. Evolution and Human Behavior, 23(3), $193-$ 201.

71. Grisso, T. (2007). Do childhood mental disorders cause adult crime? The American Journal of Psychiatry, 164(11), 1625-1627.

72. Hackman, D. A., \& Farah, M. J. (2009). Socioeconomic status and the developing brain. Trends in Cognitive Sciences, 13(2), 65-73.

73. He, J., Klag, M. J., Whelton, P. K., Chen, J., Mo, J., Qian, M., Mo, P., \& He, G. (1991). Migration, blood pressure pattern, and hypertension: the Yi migrant study. American Journal of Epidemiology, 134(10), 1085-1101.

74. Hebb, D. O. (1955). Drives and the CNS (conceptual nervous system). Psychological Review, 62(4), 243-254.

75. Heckman, J. J., Stixrud, J., \& Urzua, S. (2006). The effects of cognitive and noncognitive abilities on labor market outcomes and social behavior. Journal of Labor Economics, 24(3), 411-482.

76. Holt-Lunstad, J., Birmingham, W., \& Jones, B. Q. (2008). Is there something unique about marriage? The relative impact of marital status, relationship quality, and network social support on ambulatory blood pressure and mental health. Annals of Behavioral Medicine, 35(2), 239-244. 
77. Jennings, W. G., Piquero, A. R., \& Farrington, D. P. (2013). Does resting heart rate at age 18 distinguish general and violent offending up to age 50? Findings from the Cambridge study in Delinquent development. Journal of Criminal Justice, 41(4), 213-219.

78. Joireman, J. A., Needham, T. L., \& Cummings, A. L. (2002). Relationships between dimensions of attachment and empathy. North American Journal of Psychology, 3, 63-80.

79. Kagan, J., Reznick, J. S., Clarke, C., Snidman, N., \& Garcia-Coll, C. (1984). Behavioral inhibition to the unfamiliar. Child Development, 55(6), 2212-2225.

80. Kagan, J., Snidman, N., \& Arcus, D. (1998). Childhood derivatives of high and low reactivity in infancy. Child Development, 69(6), 1483-1493.

81. Kroeber-Riel, W. (1979). Activation research: psychobiological approaches in consumer research. Journal of Consumer Research, 5(4), 240-250.

82. Kruesi, M. J., Hibbs, E. D., Zahn, T. P., Keysor, C. S., Hamburger, S. D., Bartko, J. J., \& Rapoport, J. L. (1992). A 2-year prospective follow-up study of children and adolescents with disruptive behavior disorders: prediction by cerebrospinal fluid 5-hydroxyindoleacetic acid, homovanillic acid, and autonomic measures? Archives of General Psychiatry, 49(6), 429-435.

83. Lahey, B. B., \& Waldman, I. D. (2003). A developmental propensity model of the origins of conduct problems during childhood and adolescence. In B. B. Lahey, T. E. Moffitt, \& A. Caspi (Eds.), Causes of conduct disorder and juvenile delinquency. New York: Guilford Press.

84. Lahey, B. B., \& Waldman, I. D. (2005). A developmental model of the propensity to offend during childhood and adolescence. In D. P. Farrington (Ed.), Integrated developmental \& life-course theories of offending: advances in criminological theory (Vol. 14). New Brunswick, New Jersey: Transaction Publishers.

85. Laible, D. J., Carlo, G., \& Roesch, S. C. (2004). Pathways to self-esteem in late adolescence: the role of parent and peer attachment, empathy, and social behaviours. Journal of Adolescence, 27(6), 703-716.

86. Lawlor, D. A., Najman, J. M., Sterne, J., Williams, G. M., Ebrahim, S., \& Smtih, G. D. (2004). Associations of parental, birth, and early life characteristics with systolic blood pressure at 5 years of age - findings from the Mater-University study of pregnancy and its outcomes. Circulation, 110(16), 2417-2423.

87. Liew, J., Eisenberg, N., Losoya, S. H., Fabes, R. A., Guthrie, I. K., \& Murphy, B. C. (2003). Children's physiological indices of empathy and their socioemotional adjustment: does caregivers' expressivity matter? Journal of Family Psychology, 17(4), 584-597.

88. Loeber, R., Farrington, D. P., \& Stallings, R. (2011). The Pittsburgh Youth Study. In R. Loeber \& D. P. Farrington (Eds.), Young homicide offenders and victims: risk factors, prediction, and prevention from childhood. New York: Springer.

89. Lorber, M. F. (2004). Psychophysiology of aggression, psychopathy, and conduct problems: a metaanalysis. Psychological Bulletin, 130(4), 531-552.

90. Lösel, F., \& Bender, L. (1997). Heart rate and psychosocial correlates of antisocial behavior in high-risk adolescents. In A. Raine, P. A. Brennan, D. P. Farrington, \& S. A. Mednick (Eds.), Biosocial bases of violence. New York: Plenum Press.

91. Luecken, L. J. (1998). Childhood attachment and loss experiences affect adult cardiovascular and cortisol function. Psychosomatic Medicine, 60(6), 765-772.

92. Lykken, D. T. (1995). The antisocial personalities. Hillsdale, NJ: Lawrence Erlbaum.

93. Magnusson, D. (1988). Individual development from an interactional perspective: a longitudinal study. Hillsdale, NJ: Lawrence Erlbaum Associates, Inc.

94. Mathewson, K. J., Dywan, J., Snyder, P. J., Tays, W. J., \& Segalowitz, S. J. (2011). Autonomic regulation and maze-learning performance in older and younger adults. Biological Psychology, 88(1), $20-27$

95. Mathias, C. W., \& Stanford, M. S. (2003). Impulsiveness and arousal: heart rate under conditions of rest and challenge in healthy males. Personality and Individual Differences, 35(2), 355-371.

96. Mawson, A. R. (2009). On the association between low resting heart rate and chronic aggression: retinoid toxicity hypothesis. Progress in Neuro-Psychopharmacology and Biological Psychiatry, 33(2), 205-213.

97. McEwen, B. S. (1998). Stress, adaptation, and disease - Allostasis and allostatic load. In S. M. McCann, J. M. Lipton, E. M. Sternberg, G. P. Chrousos, P. W. Gold, and C. C. Smith (Eds.), Neuroimmunomodulation: Molecular aspects, integrative systems, and clinical advances. New York: Annals of the New York Academy of Sciences.

98. Miller, H. A. (2006). A dynamic assessment of offender risk, needs, and strengths in a sample of prerelease general offenders. Behavior Sciences \& the Law, 24(6), 767-782. 
99. Modesti, P. A., Tamburini, C., Hagi, M. I., Cecioni, I., Migliorini, A., \& Serneri, G. G. N. (1994). Twenty-four-hour blood pressure changes in young Somalian blacks after migration to Italy. American Journal of Hypertension, 8(2), 201-205.

100. Moffitt, T. E. (1993). Life-course-persistent and adolescence-limited antisocial behavior: a developmental taxonomy. Psychological Review, 100(4), 674-701.

101. Moffitt, T. E., Arsenault, L., Belsky, D., Dickson, N., Hancox, R. J., Harrington, H., \& Caspi, A. (2011). A gradient of childhood self-control predicts health, wealth, and public safety. Proceedings of the National Academy of Sciences, 108(7), 2693-2698.

102. Moffitt, T. E., \& Caspi, A. (2001). Childhood predictors differentiate life-course persistent and adolescent limited pathways among males and females. Development and Psychopathology, 13(2), 355-375.

103. Moffitt, T. E., Caspi, A., Rutter, M., \& Silva, P. A. (2001). Sex differences in antisocial behaviour: conduct disorder, delinquency, and violence in the Dunedin Longitudinal Study. United Kingdom: Cambridge University Press.

104. Moffitt, T. E., Lynam, D. R., \& Silva, P. A. (1994). Neuropsychological tests predicting persistent male delinquency. Criminology, 32(2), 277-300.

105. Morcet, J. F., Safar, M., Thomas, F., Guize, L., \& Benetos, A. (1999). Associations between heart rate and other risk factors in a large French population. Journal of Hypertension, 17(12), 1671-1676.

106. Murray, J., Farrington, D. P., \& Eisner, M. P. (2009). Drawing conclusions about causes from systematic reviews of risk factors: the Cambridge Quality Checklists. Journal of Experimental Criminology, 5(1), $1-23$.

107. Ortiz, J., \& Raine, A. (2004). Heart rate level and antisocial behavior in children and adolescents: a metaanalysis. Journal of the American Academy of Child \& Adolescent Psychiatry, 43(2), 154-162.

108. Portnoy, J., Chen, F. R., \& Raine, A. (2013). Biological protective factors for antisocial and criminal behavior. Journal of Criminal Justice, 41(5), 292-299.

109. Portnoy, J. \& Farrington, D. P. (2015). Resting heart rate and antisocial behavior: An updated systematic review and meta-analysis. Aggression and Violent Behavior.

110. Portnoy, J., Raine, A., Chen, F., Pardini, D., Loeber, R., \& Jennings, R. (2014). Heart rate and antisocial behavior: the mediating role of impulsive sensation-seeking. Criminology, 52(2), 292-311.

111. Posner, M. I., Rothbart, M. K., Sheese, B. E., \& Voelker, P. (2012). Control networks and neuromodulators of early development. Developmental Psychology, 48(3), 827-835.

112. Posthumus, J. A., Böcker, K. B. E., Raaijmakers, M. A. J., Van Engeland, H., \& Matthys, W. (2009). Heart rate and skin conductance in four-year-old children with aggressive behavior. Biological Psychology, 82(2), 164-168.

113. Poulter, N. R., Khaw, K. T., Hopwood, B. E. C., Mugambi, M., Peart, W. S., Rose, G., \& Sever, P. S. (1990). The Kenyan Luo migration study: observations on the initiation of a rise in blood pressure. British Medical Journal, 300(6730), 967-972.

114. Quay, H. C. (1965). Psychopathic personality as pathological stimulation-seeking. American Journal of Psychiatry, 122(2), 180-183.

115. Rafter, N. H. (2006). H. J. Eysenck in Fagin's kitchen: The return to biological theory in 20th-century criminology. History of the Human Sciences, 19(4), 37-56.

116. Raine, A. (2002). Annotation: the role of prefrontal deficits, low autonomic arousal, and early health factors in the development of antisocial and aggressive behavior in children. Journal of Child Psychology and Psychiatry, 43, 417-434.

117. Raine, A., Fung, A. L. C., Portnoy, J., Choy, O., \& Spring, V. L. (2014). Low heart rate as a risk factor for child and adolescent proactive aggressive and impulsive psychopathic behavior. Aggressive Behavior, 40(4), 290-299.

118. Raine, A., Venables, P. H., \& Mednick, S. A. (1997). Low resting heart rate at age 3 years predisposes to aggression at age 11 years: evidence from the Mauritius Child Health Project. Journal of the American Academy of Child \& Adolescent Psychiatry, 36(10), 1457-1464.

119. Raine, A., Venables, P. H., \& Williams, M. (1990). Relationships between central and autonomic measures of arousal at age 15 years and criminality at age 24 years. Archives of General Psychiatry, 47(11), 1003-1007.

120. Raine, A., Venables, P. H., \& Williams, M. (1995). High autonomic arousal and electrodermal orienting at age 15 years as protective factors against criminal behavior at age 29 years. American Journal of Psychiatry, 152(11), 1595-1600.

121. Raine, A., Venables, P. H., \& Williams, M. (1996). Better autonomic conditioning and faster electrodermal half-recovery time at age 15 years as possible protective factors against crime at age 29 years. Developmental Psychology, 32(4), 624-630. 
122. Raine, A., Yaralian, P. S., Reynolds, C., Venables, P. H., \& Mednick, S. A. (2002). Spatial but not verbal cognitive deficits at age 3 in persistently antisocial individuals. Development and Psychopathology, 14(1), 25-44.

123. Reznick, J. S., Kagan, J., Snidman, N., Gersten, M., Baak, K., \& Rosenberg, A. (1986). Inhibited and uninhibited children: a follow-up study. Child Development, 57(3), 660-680.

124. Richards, J. E., \& Cameron, D. (1989). Infant heart-rate variability and behavioral developmental status. Infant Behavior and Development, 12(1), 45-58.

125. Rothbart, M. K., \& Bates, J. C. (1998). Temperament. In N. Eisenburg \& W. Damon (Eds.), Handbook of child psychology: vol. 3. Social, emotional, and personality development. New York: Wiley.

126. Rothbart, M. K., Ellis, L. K., Rosario Rueda, M., \& Posner, M. I. (2003). Developing mechanisms of temperamental effortful control. Journal of Personality, 71(6), 1113-1144.

127. Roubinov, D. S., \& Luecken, L. J. (2010). Father bonding and blood pressure in young adults from intact and divorced families. Journal of Psychosomatic Research, 69(2), 161-168.

128. Salmond, C. E., Prior, I. A. M., \& Wessen, A. F. (1989). Blood pressure patterns and migration: a 14-year cohort study of adult Tokelauans. American Journal of Epidemiology, 130(1), 37-52.

129. Sampson, R. J., \& Laub, J. H. (2005). A general age-graded theory of crime: lessons learned about the future of life-course criminology. In D. P. Farrington (Ed.), Integrated developmental \& life-course theories of offending: advances in criminological theory (Vol. 14). New Brunswick, New Jersey: Transaction Publishers.

130. Scarpa, A., Fikretoglu, D., \& Luscher, K. (2000). Community violence exposure in a young adult sample: II. Psychophysiology and aggressive behavior. Journal of Community Psychology, 28(4), 417425.

131. Scarpa, A., \& Haden, S. C. (2006). Psychophysiological, behavioral, and emotional distinctions between childhood reactive and proactive aggression. Presented at the XIX world meeting of the International Society for Research on Aggression. Minnesota: Minneapolis.

132. Schmidt, B., Mussel, P., \& Hewig, J. (2013). I'm too calm—let's take a risk! On the impact of state and trait arousal on risk taking. Psychophysiology, 50(5), 498-503.

133. Schug, R. A., \& Fradella, H. F. (2014). Mental illness and crime. California: Sage Publications.

134. Sijtsema, J. J., Veenstra, R., Lindenberg, S., van Roon, A. M., Verhulst, F. C., Ormel, J., \& Riese, H. (2010). Mediation of sensation seeking and behavioral inhibition on the relationship between heart rate and antisocial behavior: The TRAILS study. Journal of the American Academy of Child \& Adolescent Psychiatry, 49(5), 493-502.

135. Sutherland, E. H. (1939). Principles of criminology (3rd ed.). Philadelphia: Lippincott.

136. Taylor, A., \& Kim-Cohen, J. (2007). Meta-analysis of gene-environment interactions in developmental psychopathology. Development and Psychopathology, 19(4), 1029-1037.

137. Taylor, S. E., Lerner, J. S., Sage, R. M., Lehman, B. J., \& Seeman, T. E. (2004). Early environment, emotions, responses to stress, and health. Journal of Personality, 72(6), 1365-1394.

138. Thornberry, T. P., \& Krohn, M. D. (2005). Appling interactional theory to the explanation of continuity and change in antisocial behavior. In D. P. Farrington (Ed.), Integrated developmental \& life-course theories of offending: advances in criminological theory (Vol. 14). New Brunswick, New Jersey: Transaction Publishers.

139. Trasler, G. B. (1962). The explanation of criminality. London: Routledge \& Kegan Paul.

140. Van Goozen, S. H. M., Farichild, G., Snoek, H., \& Harold, G. T. (2007). The evidence for a neurobiological model of childhood antisocial behavior. Psychological Bulletin, 133(1), 149-182.

141. Van Hulle, C., Zahn-Waxler, C., Robinson, J. L., Rhee, S. H., Hastings, P. D., \& Knafo, A. (2013). Autonomic correlates of children's concern and disregard for others. Social Neuroscience, 8(4), 275-290.

142. Venables, P. J. (1987). Autonomic nervous system factors in criminal behavior. In S. A. Mednick, T. E. Moffitt, \& S. A. Stack (Eds.), The causes of crime: new biological approaches. Cambridge, UK: Cambridge University Press.

143. Wadsworth, M. E. J. (1976). Delinquency, pulse rates and early emotional deprivation. British Journal of Criminology, 16, 245-256.

144. Wagner, A. D., Schacter, D. L., Rotte, M., Koutstaal, W., Maril, A., Dale, A. M., Rosen, B. R., \& Buckner, R. L. (1998). Building memories: remembering and forgetting of verbal experiences as predicted by brain activity. Science, 281(5380), 1188-1191.

145. Walsh, A. (2000). Behavior genetics and anomie/strain theory. Criminology, 38(4), 1075-1108.

146. Walters, G. D. (2011). Childhood temperament: dimensions or types? Personality and Individual Differences, 50(8), 1168-1173. 
147. Wharton, W., Hirshman, E., Merritt, P., Stangl, B., Scanlin, K., \& Krieger, L. (2006). Lower blood pressure correlates with poorer performance on visuospatial attention tasks in younger individuals. Biological Psychology, 73(3), 227-234.

148. Wikström, P. O. H. (2005). The social origins of pathways in crime: towards a developmental ecological action theory of crime involvement and its changes. In D. P. Farrington (Ed.), Integrated developmental \& life-course theories of offending: advances in criminological theory (Vol. 14). New Brunswick, New Jersey: Transaction Publishers.

149. Wilson, A. C., Lengua, L. J., Tininenko, J., Taylor, A., \& Trancik, A. (2009). Physiological profiles during delay of gratification: associations with emotionality, self-regulation, and adjustment problems. Journal of Applied Developmental Psychology, 30(6), 780-790.

150. Wilson, G. F. (1992). Applied use of cardiac and respiration measures: practical considerations and precautions. Biological Psychology, 34(2), 163-178.

151. Wilson, L. C., \& Scarpa, A. (2012). Criminal behavior: the need for an integrative approach that incorporates biological influences. Journal of Contemporary Criminal Justice, 28(3), 366-381.

152. Wilson, L. C., \& Scarpa, A. (2013). Baseline heart rate, sensation seeking, and aggression in young adult women: a two-sample examination. Aggressive Behavior, 39(4), 280-289.

153. Wilson, L. C., \& Scarpa, A. (2014). Aggressive behavior: an alternative model of resting heart rate and sensation seeking. Aggressive Behavior, 40(1), 91-98.

154. Wolfe, C. D., \& Bell, M. A. (2004). Working memory and inhibitory control in early childhood: contributions from physiology, temperament, and language. Developmental Psychobiology, 44(1), 6883.

155. Wright, J. P., \& Boisvert, D. (2009). What biosocial criminology offers criminology. Criminal Justice and Behavior, 36(11), 1228-1240.

156. Yang, Y., Gao, Y., Schug, R., Glenn, A., Peskin, M., \& Raine, A. (2011). Biosocial bases of antisocial behavior. In M. J. DeLisi \& K. Beaver (Eds.), Criminological theory: a life-course approach. Jones \& Bartlett: Boston, MA.

157. Zahn, T. P. (1986). Psychophysiological approaches to psychopathology. In M. G. H. Coles, S. W. Porges, \& E. Donchin (Eds.), Psychophysiology: systems, processes, and applications (Vol. 1). New York: Guilford Press.

158. Zahn-Waxler, C., Cole, P. M., Welsh, J. D., \& Fox, N. A. (1995). Psychophysiological correlates of empathy and prosocial behaviors in preschool children with behavior problems. Development and Psychopathology, 7(1), 27-48.

159. Zhang, J., \& Kesteloot, H. (1999). Anthropometric, lifestyle and metabolic determinants of resting heart rate - a population study. European Health Journal, 20(2), 103-110.

160. Zuckerman, M. (1991). Psychobiology of personality. Cambridge: Cambridge University Press. 